\title{
Explaining the role and relationship between spiritual intelligence and hidden anxiety and test anxiety in students: Application of path analysis
}

\author{
Research Article
}

\section{Pouriya Darabiyan', Saeed Ghanbari², Hajar Sadeghi ${ }^{3}$, Zeinab Jamshidi', Fereshteh Hadi', SimaSadat Ghaemi Zade', Alireza Rafi4*, Shahram Molavynejad5}

\author{
1.Student Research Committee, Ahvaz Jundishapur University of Medical Sciences, Ahvaz, Iran. \\ 2.Assistant professor, Department of Biostatistics and Epidemiology, School of Public Health, \\ Ahvaz Jundishapur University of Medical Sciences, Ahvaz, Iran. \\ 3. PhD Student in Nursing, Student Research Committee, University of Social Welfare and Rehabilitation Sciences, Tehran, Iran. \\ 4.MSc Student of Nursing, Student Research Committee, School of Nursing\& Midwifery, \\ Shahid Beheshti University of Medical Sciences, Tehran, Iran. \\ 5.Faculty of Nursing and Midwifery, Nursing Care Research Center in Chronic Disease, \\ Ahvaz Jundishapur University of Medical sciences, Ahvaz, Iran.
}

\begin{abstract}
Objective: Spiritual intelligence is manifested when a person spends his life in complete spirituality. Anxiety and test anxiety are among the most common psychological and emotional problems during student life that have a negative impact on students' mental health and academic performance. Therefore, this study was conducted to explain the role and relationship between spiritual intelligence and hidden anxiety and test anxiety. Methods: This analytical study was performed on 503 nursing and midwifery students of Ahvaz Jundishapur University of Medical Sciences, Ahvaz, Iran (2018) using the available sampling method. King spiritual intelligence scale, Sarason's test anxiety scale, and Spielberger Anxiety Questionnaire were used to collect data. To analyze the data, statistical methods of path analysis and correlation coefficients were used. Results: The overall effect of test anxiety variable on spiritual intelligence variable is 0.1632 and the overall effect of hidden anxiety variable on spiritual intelligence variable is -0.07. Spiritual intelligence has a significant relationship with test anxiety, so that with increasing mental intelligence, test anxiety is decreased. While in the case of significant relationship between spiritual intelligence and hidden anxiety, with increasing spiritual intelligence, hidden anxiety is also increased. There was no significant relationship between hidden anxiety and test anxiety. The two variables of hidden anxiety and test anxiety have a very weak effect on spiritual intelligence. The effect of hidden anxiety is not significant at all, and the effect of test anxiety is very weak, although being significant. Conclusion: High spiritual intelligence indicates lower test anxiety, while it is inversely related to hidden anxiety. As a result, high spiritual intelligence does not indicate less hidden anxiety in individuals. So it cannot be said for sure that spiritual intelligence plays an important role in reducing anxiety.
\end{abstract}

Key Words: Spiritual Intelligence, Hidden Anxiety, Test Anxiety, Students, Iran.

\section{Introduction}

Intelligence is an ability to adapt to new problems and situations in life (1), which has long been interested in research and research on its various types and related features (2). On the other hand, intelligence is important in strengthening learning and adapting to the environment (3). One of the characteristics of smart people is to provide a fundamental solution and find efficient ways to solve various problems (2). Another aspect of intelligence that, from the experts' point of view, is only for humans, is called spiritual intelligence

* Corresponding Author:

\section{Alireza Rafi}

MSc Student of Nursing, Student Research

Committee, School of Nursing \&Midwifery, Shahid

Beheshti University of Medical Sciences,

Tehran, Iran

Email Id: alirezarafi72@gmail.com
(4), which is also known as the root of other intelligences (5). Spiritual intelligence includes a kind of adaptation and problem-solving behavior, which increases a person's resilience to problems and helps while coordinating with the surrounding phenomena and achieving internal and external integration, as well as to people in any field. Helps to develop their spiritual awareness, capacity and consciousness (6-8). This intelligence raises questions such as: Does my job cause me to evolve in life? Or am I involved in making people happy? It comes to mind (9). According to King, spiritual intelligence has four scales: critical existential thinking, personal meaning production, transcendental awareness, and conscious state expansion (10). In Islam, spiritual intelligence is divided into seven areas, which include: soul, heart, faith and worship, and show the importance of this intelligence from the Islamic point of view (11). Spiritual abilities can have positive effects on people's social and cultural lives, so that spirituality has recently been considered as an important aspect of human beings that has a significant 
relationship with improving health $(12,13)$. Research has shown that spirituality improves a person's mental health, which is associated with positive results such as increased self-confidence and reduced anxiety (14). According to Pidmont (1999), spiritual intelligence as the inner core of the "self" can bring peace to a person in stressful situations (6). On the other hand, spiritual intelligence is manifested when a person spends his life with complete spirituality, and the use of this intelligence increases adaptability and, as a result, people's mental health (14). As a result of the study of Charkhabi et al. (2014), it was shown that spiritual intelligence reduces interpersonal sensitivity, depression, paranoid thoughts, aggression and anxiety (15). One of the effective indicators of mental health is the lack of stress, anxiety and depression (16). Research shows that anxiety, as a major disorder, affects a person's mental health. Anxiety disorder, on the other hand, is the most common mental disorder in all age groups (17). Anxiety is one of the most common psychological and emotional problems during student life. In this regard, the results of studies showed that anxiety has become an integral part of students' lives. A study by Macauley et al. (2018) conducted to determine the prevalence of anxiety in students in the United States showed that in $83 \%$ of student's anxiety was more than normal (18). On the other hand, in the studies conducted, the findings indicate a significant relationship between spiritual intelligence and anxiety in students (19). In addition to anxiety disorder, exam anxiety is an important and common educational problem among students that in addition to the negative impact on academic performance and motivation to progress affects students' mental health (20). In fact, test anxiety is a set of cognitive, physiological, and behavioral responses that are concerned about the possible negative consequences of failing an exam or a similar assessment situation. Exam anxiety can reduce students' performance during the exam or their academic achievement by interfering with exam preparation (21). On the other hand, most students get good grades during the semester, but in the final exams of the semester, they are faced with a drop in grades, which may be due to their high level of anxiety (22). Considering that in recent years the use of spiritual resources in solving life's problems has been considered $(14,23)$. In the study of Jamshidi et al. (2017), the results of the study showed a negative and significant relationship between spiritual intelligence and students' test anxiety (24). Thus, it seems that spiritual intelligence with a specific mechanism reduces test anxiety, and some spiritual skills are effective in reducing test anxiety $(25,26)$. In fact, such results are not far-fetched for Iranian society, which is religious and inclined to spiritual values (27). Despite this research, according to Amram (2009), spiritual intelligence is still one of the areas where coherent and systematic research has not been conducted to identify its characteristics (28). Therefore, due to the high prevalence of anxiety and especially test anxiety, which is important for students due to the loss of young and talented people in the country, as well as the sensitivity of medical sciences, especially nursing and midwifery, which are closely related to public health. And spiritual intelligence is considered as one of the factors of academic and clinical success, as well as the lack of a study in the country that simultaneously measures hidden anxiety and test anxiety in relation to spiritual intelligence. Given the importance of the nursing and midwifery student community as one of the country's largest groups and as a future medical staff and the importance of the role of anxiety in reducing their performance, Ahvaz Jundishapur University of Medical Sciences was performed.

\section{Materials and Methods}

This descriptive-analytical study was performed on 503 students of the School of Nursing and Midwifery of Ahwaz Jundishapur University of Medical Sciences using the available sampling method in a period of 3 months (April 18 to July 9, 2018). Before distributing the questionnaires, explanations were given about the objectives of the research, how to answer the questions, the confidentiality of the information, the optional company and the announcement of future results in general, and after obtaining consent from the participants, the questionnaires were distributed and then they were collected simultaneously.

The data collection tools included four parts: demographic information, King's Spiritual Intelligence Self-Report Inventory, Sarason's test anxiety scale and Spielberger Anxiety Questionnaire. Demographic information questionnaire included: age, gender, semester, father's job, place of residence (Native), was the average of the previous semester and the marital status. King's spiritual intelligence scale has 24 items and has 4 subscales, including: Critical Existential Thinking, Personal Meaning Production, Transcendental Awareness, and Conscious State Expansion development. The Likert is a five-choice option that includes: completely incorrect (0), incorrect (1), somewhat correct (2), very true (3), and quite true (4). Scoring methods in question 6 is reversed. The higher the score on this questionnaire is to be a more spiritual intelligence. (29) In the study of Raqib et al. (2010), the reliability of this scale was estimated using Cronbach's alpha coefficient of 0.88 . The formal validity and content of the scale were confirmed by psychologists. To estimate the convergence narrative, the Bonab Dust Spiritual Experience Questionnaire was used simultaneously, and the correlation coefficients of these two questionnaires were 0.66 . To calculate the validity of the scale structure, the exploratory factor analysis and the first-order confirmatory factor analysis were used. The results showed that this scale is a reliable tool for measuring spiritual intelligence and due to its validity and reliability, it can be used in educational and research environments such as the university (30).

Sarason's test anxiety scale has 37 items that are answered correctly or incorrectly within 10 to 15 minutes. The higher a person's score on this questionnaire, the greater the anxiety of the exam. Also, for each correct answer to other questions, a score is 
considered. After collecting the scores, the individual's test anxiety score is obtained. The higher the score, the higher the test anxiety, and the person is ranked in one of these three categories according to the score obtained (mild anxiety score less than 12 , average anxiety score 12 to 20 , and severe anxiety 21 and above) (31). The validity and reliability of this questionnaire were measured in several studies and obtained with alpha Cronbach's coefficient of 0.88 and internal similarity of 0.95 and standard validity equal to 0.72 , which is generally acceptable (32).

Spielberger's anxiety questionnaire contains 40 questions, from questions 1 to 20 dedicated to state anxiety and from questions 21 to 40 dedicated to adjective anxiety. Question Anxiety Questions in the Likert range are four scoring options that are: by no means, sometimes, generally, too much. And the questions about adjective anxiety are given in the same way as the 4 scoring options, which are: almost never, sometimes, most of the time, and almost always. Finally, two scores are obtained. Anxiety is an adjective. Each person can score between 20 and 80 in these two types of anxiety. In this study, 20 questions related to state anxiety were used to measure hidden anxiety. Moderate anxiety as mild anxiety (grades 20 to 31 ), moderate to low (grades 32 to 42 ), moderate to high (grades 43 to 52 ), relatively severe (grades 53 to 62), severe (grades 63 to 72), Is highly rated (score 73 and above). Questions 136710131416 and 19 are scored in reverse (33). In a study of Taghavi et al., Which was performed on 219 patients with generalized anxiety disorder, major depression and normal individuals, Cronbach's alpha coefficient was 0.92 on the anxiety scale and 0.90 on the anxiety scale (34).

Descriptive statistics were used to describe the data collected from the statistical data. An independent t-test was used to examine the mean difference between the quantitative variables. To examine the relationship between spiritual intelligence and its dimensions, hidden anxiety and test anxiety with gender, place of residence, marital status of $T$ test and also the relationship between spiritual intelligence and its dimensions, hidden anxiety and test anxiety with academic semester and father's job, (ANOVA) has been used. The correlation coefficient test was used to investigate the relationship between age and GPA of the last semester with the mentioned variables. In this study, a data analysis model was used to determine the relationship between the variables of spiritual intelligence, test anxiety and hidden anxiety to the data. In path analysis, a theoretical model is tested, which eventually leads to an experimental model by performing the analysis. Therefore, it is natural that the causal relationship between the variables in the experimental model that results from path analysis is always constructed. The difference (with the theoretical model) that is obtained from the theoretical framework is different. The general rule is that in path analysis, variables whose beta value is not less than 0.05 are removed from the model (35).

In path analysis, both cause and effect variables are measurable. In fact, the correlation coefficient of each cause-and-effect variable is divided into two parts, including direct and indirect effects. That is why the correlation coefficient should not be the basis of judgment alone. Also, the existence of correlation between the two variables may be due to the existence of another variable that has affected both variables and has caused the correlation between the two variables and in fact there is no causal relationship between the two variables. (36). In the present study, in order to perform path analysis, the variables that were correlated with test anxiety and hidden anxiety entered the path model and the paths were determined based on theoretical theories and then the final model was determined using fitness indicators. Given that spiritual intelligence is a multidimensional factor and each of these dimensions affects the other, to examine the direct and indirect effects, as well as the overall effect of each dimension of spiritual intelligence on test anxiety and hidden anxiety of equation models. Structural Equation Modeling and Path analysis methods were used. Statistical analysis was performed by SPSS software version 22 and Amos version 16.

\section{Results}

In this study, the mean and standard deviation of students' age and grade point average were 21.52 \pm 2.64 and $16.69 \pm 7.02$ respectively. Other information on student demographic specifications is given in Table 1. The relationship between test anxiety and dormitory status, marital status, semester, and father's occupation was not statistically significant $(\mathrm{P}<0.05)$ but was significantly associated with gender $(\mathrm{P}<0.05)$. Concealed anxiety was associated with drowsiness and marital status $(\mathrm{P}<0.05)$ and no significant relationship with other variables $(\mathrm{P}<0.05)$. Also, a relationship between spiritual intelligence and gender (total score of spiritual intelligence and subscales of transcendent consciousness and critical existential thinking) and age (total score of spiritual intelligence and subscales of critical existential thinking and expansion of state of consciousness) was observed to be significant $(\mathrm{P}<0.05)$

The average score of students' hidden anxiety was $54.25 \pm 10.28$ of which $89.7 \%$ had hidden anxiety (Table 2) and the mean test anxiety score was 57.80 with a standard deviation of 6.97 , with $83.5 \%$ experiencing test anxiety (Figure 1). The Average students' spiritual intelligence was $57.78 \pm 15.13$. The mean values obtained for the dimensions of spiritual intelligence are shown in Figure 2 (higher values indicate higher spiritual intelligence). The results of Pearson correlation test show that it has a significant relationship with spiritual intelligence with test anxiety, so that with increasing mental intelligence, test anxiety decreases, while having a significant relationship between spiritual intelligence and hidden anxiety, with increasing intelligence, spiritually and hidden anxiety also increases. There was no significant relationship between latent anxiety and test anxiety (Table 3).

Spiritual intelligence variable is a hidden variable that is derived from four defined dimensions. Also, the other two observed variables have been 
studied under the heading of hidden anxiety and test anxiety and how they have affected the level of spiritual intelligence and each other. According to the model and results of the above table, the effect of each dimension on the level of spiritual intelligence is significant and this rate is very strong. The greatest impact is on the dimension of expanding the conscious state expansion and the least on the dimension of personal meaning production. It should be noted that the impact of each dimension on the level of spiritual intelligence is extremely strong.

The two variables of hidden anxiety and test anxiety have a very weak effect on spiritual intelligence. The effect of hidden anxiety is not significant at all, and the effect of test anxiety, although significant, is very weak. (Hidden anxiety and test anxiety are not significantly related). In other words, the variability of the spiritual intelligence variable is from the four mentioned dimensions, not from the two variables of test anxiety and hidden anxiety. Although the spiritual intelligence variable is affected by the test anxiety variable, this influence is so low that it can be ignored. The direct effect of the test anxiety variable on the spiritual intelligence variable is 0.16 . The direct effect of the test anxiety variable on the spiritual intelligence variable is 0.0032 . The overall effect of the test anxiety variable on the spiritual intelligence variable is 0.1632 .

To evaluate the suitability of the path analysis model, Comparative Fit Index (CFI) and Tucker-Lewis Index (TLI) were calculated. If the value of these indicators is more than 0.9 , they indicate the good fit of the model, in which case the proposed model is welladjusted (Table 4). The Root Mean Square Error of Approximation (RMSEA) is used in most confirmatory factor analyzes and structural average models. If the value of this index is less than 0.05 , the fit of the model is good, and if it is between 0.05 and 0.08 , the fit of the model is medium. According to the results of Table 3, this index is less than 0.05 and shows that the model is well fitted. One of the general indicators for calculating the free parameters in calculating the fitness indicators of the K-2 standard is normal, which is obtained by simply dividing K-2 by the degree of freedom, and you can see this index in Table 4. The RMSEA index means the root of the remaining average square. The closer this criterion is to zero, the higher the fit of the model. According to the above model, the value of this index is very low, which shows that the model is well-fitted. Akaike information criterion (AIC) and ChwartzBayesian Information Creterion (BIC) are used to compare different models, each model that has less of these indicators is a more appropriate model.

\section{Discussion}

The present study was conducted to investigate the relationship between spiritual intelligence and hidden anxiety and test anxiety of students. In this study, the average spiritual intelligence of students is at the intermediate level, which is consistent with the findings of Heravi and Samiari study $(22,37)$. Mohebbi and Ghana found in their study that the average score of spiritual intelligence was high $(1,38)$, but Hamid and his colleagues reported a low level of spiritual intelligence in their study (39). This difference in studies can be due to the use of different tools, cultural differences and the values and beliefs of each person based on the geographical location of his life.

In the present study, there was a significant relationship between spiritual intelligence and gender, which was in line with the study of George et al. (2013) (40). However, in some studies, no significant relationship was found between gender and spiritual intelligence $(22,41)$. Also, in this study, a significant relationship was observed between the score of spiritual intelligence and the age of students. The results of the study of samyarism also showed a significant relationship between spiritual intelligence and age (37). No significant relationship between spiritual intelligence and age was observed in Heravi's study (22). This difference is possible. Due to the consideration of age in terms of interval and lack of questions about age is accurate.

Based on the results of Pearson correlation test in the present study, there was an inverse relationship between test anxiety and spiritual intelligence. As mental intelligence increases, test anxiety decreases. In the study of Khorami Rad et al. (2013), the relationship between spiritual intelligence and exam anxiety was performed on 246 nursing and midwifery students. The results showed that there is an inverse relationship between spiritual intelligence and exam anxiety, which is in line with the results. This study (14). Khazaei's study (2010) also showed that there is a significant relationship between religious beliefs and test anxiety in students (42).

Also, based on the results of Pearson correlation test in the present study, having a significant relationship between spiritual intelligence and hidden anxiety, with increasing spiritual intelligence, hidden anxiety also increases. But there was no significant relationship between hidden anxiety and test anxiety. Considering the general relationship between the dimensions of spiritual intelligence and test anxiety, the factor analysis model and the path model to examine the direct and general effects of dimensions showed that the effect of each dimension on the level of spiritual intelligence is significant and this rate is very strong. At the same time, the greatest effect is related to the dimension of expanding the state of consciousness and the least related to the dimension of producing personal meaning. It should be noted that the impact of each dimension on the level of spiritual intelligence is extremely strong.

In the present study, based on the model, the two variables of hidden anxiety and test anxiety have a very weak effect on spiritual intelligence. So the effect of hidden anxiety is not significant at all, and the effect of test anxiety, although significant, is very weak. In other words, the variability of the spiritual intelligence variable from the dimensions of critical existential thinking is the production of personal meaning, transcendent consciousness, and the expansion of the state of consciousness (not the two variables of hidden 
anxiety and test anxiety). Although the spiritual intelligence variable is affected by the test anxiety variable, this influence is so low that it can be ignored. The direct effect of the test anxiety variable on the spiritual intelligence variable is 0.16 . The direct effect of the test anxiety variable on the spiritual intelligence variable is 0.0032 . The overall effect of the test anxiety variable on the spiritual intelligence variable is 0.1632 . In confirmation of this, it has been observed in some studies that there is no significant relationship between spiritual performance such as endurance in religious affairs and test anxiety $(43,44)$.

It should also be noted that spiritual intelligence, as a cognitive and motivating factor, enables a person to have a more efficient response to problem solving by evaluating and interpreting secondary and spiritual situations, and thus with a positive and purposeful attitude towards Life has more mental health than others. (45) Therefore, various factors affect spiritual intelligence and can affect the relationship between spiritual intelligence and exam. In the study of Jamshidi et al. (2017), it was shown that in the relationship between test anxiety and spiritual intelligence, the two variables of resilience and selfefficacy have a mediating role and the effect of selfefficacy on this relationship is more effective (24).

Various studies have also shown a positive and significant relationship between self-efficacy and spiritual intelligence $(14,46)$ and some studies have emphasized the role of self-efficacy in reducing test anxiety $(47,48)$. In some studies, the relationship between spiritual intelligence and resilience and its inverse relationship with test anxiety have been mentioned $(49,50)$. In addition to reducing test anxiety, self-efficacy and resilience are also effective in increasing mental health and academic performance $(51,52)$.

In the present study, $89.7 \%$ of people had latent anxiety and also most of the $83.5 \%$ had test anxiety experience. A study by Clark et al. (1998) found that most of the units surveyed experienced high levels of test anxiety (53). In a study by Hoying et al. (2020), $14 \%$ of students reported severe to very severe anxiety. Factors that predicted depression and anxiety included less than 7 hours of sleep per night, deteriorating general health, decreased belief in a healthy lifestyle, reduced healthy lifestyle behaviors, higher stress, and lack of control (54). The results of some different studies have shown that test anxiety can reduce students' academic performance (GPA) $(55,56)$. In addition to the impact of anxiety on GPA and students' theory of performance, their clinical performance can also be affected. So that the level of anxiety is inversely related to students' clinical performance (57).

The results of a study by Custer et al. (2018) showed that test anxiety makes nursing students unable to perform their academic duties and affects their academic performance, leading to failure in the test. Anxiety testing of nursing students may cause academic delays as a coping mechanism (58). In general, moderate anxiety levels are known to be an important factor in students' learning, but excessive anxiety may reduce learning (59). According to the Learning Areas Model (60), anxiety is seen as relieving students' fear attacks in learning, and there is also evidence that students learn the most when they are exposed to moderate levels of anxiety. (61).

Today, due to the different needs of patients in hospitals and other medical centers, care has played a special role in the treatment of diseases among medical staff, especially nurses. Therefore, holistic care reform is considered as the basic center of nurses' activities. That is, the treatment of patients should be psychological, spiritual, and environmental in all biological dimensions, not just the elimination of physical symptoms $(62,63)$. In some studies, by identifying the role of spirituality as one of the most important aspects of human health, nurses are required to examine the spiritual needs of patients (64). Stressors also affect the clinical performance of nurses and nursing students. So that the level of anxiety is inversely related to students' performance (65).

In this study, the study population was a group of nursing and midwifery students and its generalization to other populations is limited. Therefore, it is suggested that similar studies be performed in other populations as well, in order to identify other interfering factors. Also, longitudinal studies should be used to more accurately prove the relationship between spiritual intelligence and its dimensions with hidden anxiety and test anxiety.

\section{Conclusion}

An important finding from the present study was the role of spiritual intelligence in controlling test anxiety. However, it should be noted that according to the model of this research, it should be noted that not every person with higher spiritual intelligence necessarily has lower test anxiety. Therefore, the role of multiple and intermediate factors in the educational process should be considered. The learning process should be carefully considered. It is hoped that the results of the present study will be of interest to nursing education officials and planners and will be a solution to improve and promote the mental health of students and, consequently, the quality of education.

\section{Acknowledgments}

This article is the result of a research project approved by the Research Council of Ahvaz Jundishapur University of Medical Sciences No. 96s57 and the code of ethics of IR.AJUMS.REC.1396.1122. Researchers express their gratitude to the students participating in this study, the Vice Chancellor for Research, and the officials of the School of Nursing and Midwifery of Ahvaz Jundishapur University of Medical Sciences.

\section{Conflict of interest}

There is no conflict of interest for the authors in this study. 


\section{References}

1. Ghana S, Jouybari L, Sharif Nia S, Hekmatafshar M, Sanagoo A, Chehregosha M. Correlation of spiritual intelligence with some of demographic and educational factors among the students of Golestan University of Medical Sciences. Journal of Health Promotion Management. 2013;2(1):17-23. [persian]

2. Ghobari Bonab B SM, Salyani L, Noori Moghadam N. . [Spiritual Intelligence]. Andishe- E- Novin- EDini. 2007;3(10):125-46. [persian]

3. Kharrazi SK HET, Sternberg R (Author). [Cognitive Psychology]: Tehran samt; 2008.

4. McDonald AS. The prevalence and effects of test anxiety in school children. Educational psychology. 2001;21(1):89-101. [persian]

5. Naderi F AP, Roshani KH, Mehri Adaryani M. . Midwifery and Nursing Students' Emotional Intelligence and Its Relation to Spiritual Intelligence. Iranian Journal of Medical Education. 2016;16:232-41. [persian]

6. Piedmont RL. Does spirituality represent the sixth factor of personality? Spiritual transcendence and the five-factor model. Journal of personality. 1999;67(6):985-1013.

7. McSherry W, Draper P, Kendrick D. The construct validity of a rating scale designed to assess spirituality and spiritual care. International Journal of Nursing Studies. 2002;39(7):723-34.

8. Koohbanani SE, Dastjerdi R, Vahidi T, Far M-HG. The relationship between spiritual intelligence and emotional intelligence with life satisfaction among birjand gifted female high school students. Procedia-Social and Behavioral Sciences. 2013;84:314-20. [persian]

9. Cassady JC. The influence of cognitive test anxiety across the learning-testing cycle. Learning and instruction. 2004;14(6):569-92.

10. Erfan A, Haghani F, Omid A, Baratali M. Midwifery and nursing students' emotional intelligence and its relation to spiritual intelligence. Iranian Journal of Medical Education. 2016;16:232-41. [persian]

11. Baharuddin EB, Ismail ZB. 7 Domains of spiritual intelligence from Islamic perspective. ProcediaSocial and Behavioral Sciences. 2015;211:568-77. [persian]

12. Faribors B, Fatemeh A, Hamidreza H. The relationship between nurses' spiritual intelligence and happiness in Iran. Procedia-Social and Behavioral Sciences. 2010;5:1556-61. [persian]

13. AR. R. [Spiritual intelligence approaches and challenges]. Educational Journal of Islamic Azad University of Bojnourd. 2009;5(22).

14. Khoramirad A, Arsangjang S, Ahmaritehran H, Dehghani $H$. The relation between spiritual intelligence and test anxiety among nursing and midwifery students: application of path analysis. Iranian journal of medical education. 2013;13(4):319-30. [persian]

15. Charkhabi M, Mortazavi A, Alimohammadi S, Hayati D. The effect of spiritual intelligence training on the indicators of mental health in Iranian students: An experimental study. Procedia-Social and Behavioral Sciences. 2014;159:355-8. [persian]

16. Johnson SJ, Batey M, Holdsworth L. Personality and health: The mediating role of trait emotional intelligence and work locus of control. Personality and Individual Differences. 2009;47(5):470-5.

17. Somers JM, Goldner EM, Waraich P, Hsu L. Prevalence and incidence studies of anxiety disorders: a systematic review of the literature. The Canadian Journal of Psychiatry. 2006;51(2):100-13.

18. Macauley K, Plummer L, Bemis C, Brock G, Larson C, Spangler J. Prevalence and predictors of anxiety in healthcare professions students. Health Professions Education. 2018;4(3):176-85.

19. Bayrami M, Movahedi Y, Movahedi M. The role of spiritual intelligence in perceived stress, anxiety and depression of Lorestan Medical University Students (Iran). Journal of Babol University of Medical Sciences. 2014;16(1):56-62. [persian]

20. Jenaabadi H, Nastiezaie N, Jalalzaei S. The effect of time management training on student's test anxiety. Journal of nursing education. 2016;5(1):12-22. [persian]

21. Núñez Peña MI, Suárez Pellicioni M, Bono Cabré R. Gender differences in test anxiety and their impact on higher education students' academic achievement. Procedia-Social and Behavioral Sciences, 2016, vol 228, p 154-160. 2016.

22. Heravi M, Jadid Milani M, Regea N, Valaie N. The effect of relaxation training on exam driven anxiety level among nursing students. Journal of Mazandaran University of Medical Sciences. 2004;14(43):86-92. [persian]

23. Hosseini Z AH, editor The Relationship between Spiritual Intelligence and Anxiety Level in girl Second High School Students of West Islamabad. InFirst International Congress of Comprehensive Psychology of Iran; 2015; Tehran Center for Development of Iran [persian].

24. Jamshidi MA, Moghadam MF, Ghorbani S, Farhoush M. Self-efficacy and resilience as mediators in the relationship between test anxiety and spiritual intelligence among high school students in Qom. Journal of Research on Religion \& Health. 2017;4(1):7-21. [persian]

25. Torres KM, Turner JE. Students' foreign language anxiety and self-efficacy beliefs across different levels of university foreign language coursework. Journal of Spanish Language Teaching. 2016;3(1):57-73.

26. Erzen E, Odac1 H. The effect of the attachment styles and self-efficacy of adolescents preparing for university entrance tests in Turkey on predicting test anxiety. Educational Psychology. 2016;36(10):1728-41.

27. Nouhi E, Nakhaee N, Rahimi N. Spiritual intelligence and attitude towards spirituality and spiritual care in nursing and midwifery students. Iran Journal of Nursing. 2014;27(90):150-9. [persian] 
28. Amram JY. The contribution of emotional and spiritual intelligences to effective business leadership: Institute of Transpersonal Psychology; 2009.

29. DeCicco DBKTL. A viable model and self-report measure of spiritual intelligence. ranspersonal Studies. 2009;28:68-85.

30. Raghib M, Siadat A, Hakiminiya B, Ahmadi J. The validation of Kings' spiritual intelligence scale (SISRI-24) among students at University of Isfahan. Journal of Achievements of Psychology of ShahidChamran University of Ahvaz. 2010;4(3):3-17. [persian]

31. Sarason IG. The test anxiety scale: Concept and research. WASHINGTON UNIV SEATTLE DEPT OF PSYCHOLOGY; 1977.

32. Beyabangard. test Anxiety. Tehran: A Farhange Eslami Press; 2007.

33. Spielberger CD, Gorsuch RL. State-trait anxiety inventory for adults: Manual and sample: Manual, instrument and scoring guide: Consulting Psychologists Press; 1983.

34. Taghavi M, Najafi M, Kianersi F, Aghayan S. Comparing of alexithymia, defensive styles and state-trait anxiety among patients with generalized anxiety disorder major depression disorder and normal individuals. 2013. [persian]

35. F. G. Analysis of the relationship between physical and mental health disorders and social skills in students. social Psychology. 2017;2(40):59-74.

36. [Persian] GV-. A Beginner To Structural Equation Model. .1 st ed. T ed. ehran: Jame-e Shenasan;; 2009.

37. Semyari H, Heravi-Karimooi M, Nasiri M, Arabi F. The relationship of Dentistry students' spiritual intelligence to general health. Iranian Journal of Psychiatric Nursing. 2015;3(1). [persian]

38. Mohebbi P RL, Jafari A, Sepehrinia M Spiritual intelligence in nursing college students and its correlation with demographic variables. . Journal of Nursing Care. 2012;2(2):29-56. [persian]

39. Hamid N KM, BABAMIRI M, DEHGHANI M. . The relationship between mental health, spiritual intelligence with resiliency in student of Kermanshah University of Medical Sciences. Jentashapir Journal. 2012;3(1):331-6. [persian]

40. M. G. Practical application of spiritual intelligence in the workplace. Human Resource Management International Digest. 2006;14(5):2-5.

41. Yang KP WX. intelligence Spititual sociacal Chinese nurses in two systems: a comparative cross-sectional study. J nursery Research. 2009;17(3):98-189.

42. Khazaei H RM, Ghadami MR , Tahmasian M, Ghasemi Mobarra A, Shiri A. . Relationship between religious values and anxiety among Kermanshah University of Medical Sciences students Journal of Kermansha University of Medical ScienceS. 2010;14(1). [persian]

43. Mahin Rasuli A MM, Badri R. . Study of relationship between religious and nonreligious causal attributions with test anxiety of third year high school girls in Tabriz. Behavioral Sciences. 2012;4(11):61-79. [persian]

44. Barzegarbafruiee M JM, Neyusha B. . The role of "religious commitment" and "gender" in the "test anxiety. . Islamic studies and psychology. 2016;2012(6):43-61.

45. Sisk DA TEB, 2001. spiritual intelligence: Developing higher consciousness. New York: Creative Educatin Foundation Press;. 2001.

46. S. Ns. The relationship between spiritual intelligence and emotional intelligence and selfefficacy in students of Islamic Azad University of Dezful. Psychology and religion 2016;9(1):107-22.

47. Mombeyni s mg, behrozi $\mathrm{n}$. The Effect of Academic Self-Efficacy and Metacognition on Test Anxiety and Academic Help -Seeking Behavior in 3rd Grade High School Boys. Knowledge \& Research in Applied Psychology. 2015;16(3):42-8. [persian]

48. Mirsamiee M Egs. The relationship between selfefficacy, social support and test anxiety and mental health of male and female students of Allameh Tabatabai University. Psychology. Educational Psychology and Educational Sciences. 2007;7(2):73-92. [persian]

49. Khosravi M NZ. Relationship of Spiritual Intelligence With Resilience and Perceived Stress. Iran J Psychiatry Behav Sci. 2014;8(4):52-6. [persian]

50. Khodabakhshykulayee A Hs, Khoshkonesh A, Heidari M. The relationship of spiritual intelligence and resilience to stress and preferred mode of delivery among pregnant women. Journal of Obstetrics Gynecology and Infertility. 2013;16(58):8-15. [persian]

51. Aerabian A KM, Heidari M, Saleh Sedghpour B. The relationship between selfefficacy beliefs on mental health and educational success. Journal of Psychology. 2004;32(8):360-71. [persian]

52. Behdani S DR, Sharifzadeh GR. . Relationship between trust in God and self-efficacy With mental health in type II diabetics. Journal of Birjand University of Medical Sciences. 2012;19(3):302-11. [persian]

53. Clark JW FP, Sheneider HG. Feedback. test anxiety and performance in a college course. Psycho Rep. 1998;82(1):203-8.

54. Hoying J MB, Hutson E, Tan A. . Prevalence and Correlates of Depression, Anxiety, Stress, Healthy Beliefs, and Lifestyle Behaviors in First-Year Graduate Health Sciences Students. Worldviews on Evidence-Based Nursing. 2020.

55. Hong E KL-. Antecedents of state test anxiety. Contemporary Educational Psychology. 2002;27(2):348-67.

56. JC C. The influence of cognitive test anxiety across the learning-testing cycle. Learning and Instruction. 2004;14(6):569-92.

57. Yerkes RM DJ. The relation of strength of stimulus to rapidity of habit-formation. Journal of 
comparative neurology and psychology. 1908; 18(5):459-82.

58. N. C. Test anxiety and academic procrastination among prelicensure nursing students. Nursing education perspectives. 2018;39(3):162-3.

59. Al-Ghareeb A ML, Cooper S. The influence of anxiety on student nurse performance in a simulated clinical setting: A mixed methods design. 2019 Oct 1;98:57-66. The influence of anxiety on student nurse performance in a simulated clinical setting: A mixed methods design. International journal of nursing studies. 2019;98:57-66.

60. Hayden JK SR, Alexander M, Kardong-Edgren S, Jeffries PR. The NCSBN national simulation study: A longitudinal, randomized, controlled study replacing clinical hours with simulation in prelicensure nursing education. . Journal of Nursing Regulation. 2014.
61. Palethorpe R WJ. Learning in the panic zone: Strategies for managing learner anxiety. Journal of European Industrial Training. 2011.

62. Mitchell M HJ. Teaching spirituality to student midwives: a creative approach. Nurse Educ Pract. 2007;7(6):416-24.

63. Cooper KL CE, Sheehan A, Johnson A. . The impact of spiritual care education upon preparing undergraduate nursing students to provide spiritual care. Nurse Educ Today. 2013;33(9):1057-61.

64. KB. W. Professional, ethical, and legal implications for spiritual care in nursing. Image: $J$ Nurs Scholarsh. 1998;30(1):81-3.

65. Yerkes RM DJ. The relation of strength of stimulus to rapidity of habit-formation. Journal of comparative neurology and psychology. 1908;18(5):459-82.

Table 1. Demographic characteristics of the participants

Variable

\begin{tabular}{|c|c|c|}
\hline \multicolumn{2}{|c|}{ Variable } & \multirow{2}{*}{$\begin{array}{c}\text { n (Percent) } \\
360(71.6)\end{array}$} \\
\hline Gender & Female & \\
\hline & Male & $143(28.4)$ \\
\hline \multirow{2}{*}{ Marriage } & Single & $455(90.5)$ \\
\hline & Married & $48(9.5)$ \\
\hline \multirow[t]{3}{*}{ Father's job } & Employee's & $203(40.5)$ \\
\hline & Free & $208(41.4)$ \\
\hline & Retired & $92(18.3)$ \\
\hline \multirow[t]{2}{*}{ Accommodation in a dormitory } & Yes & $379(75.3)$ \\
\hline & No & $124(24.7)$ \\
\hline
\end{tabular}

Table 2. Percentage of people in terms of hidden anxiety status

\begin{tabular}{|c|c|c|}
\hline Dimensions & Frequency & Percent \\
\hline Mild anxiety & 83 & 16.5 \\
\hline Medium to low anxiety & 287 & 57.1 \\
\hline Moderate to high anxiety & 78 & 15.5 \\
\hline Relatively severe anxiety & 3 & 0.6 \\
\hline No anxiety & 52 & 10.3 \\
\hline
\end{tabular}

Figure 1: Percentage of people in terms of test anxiety

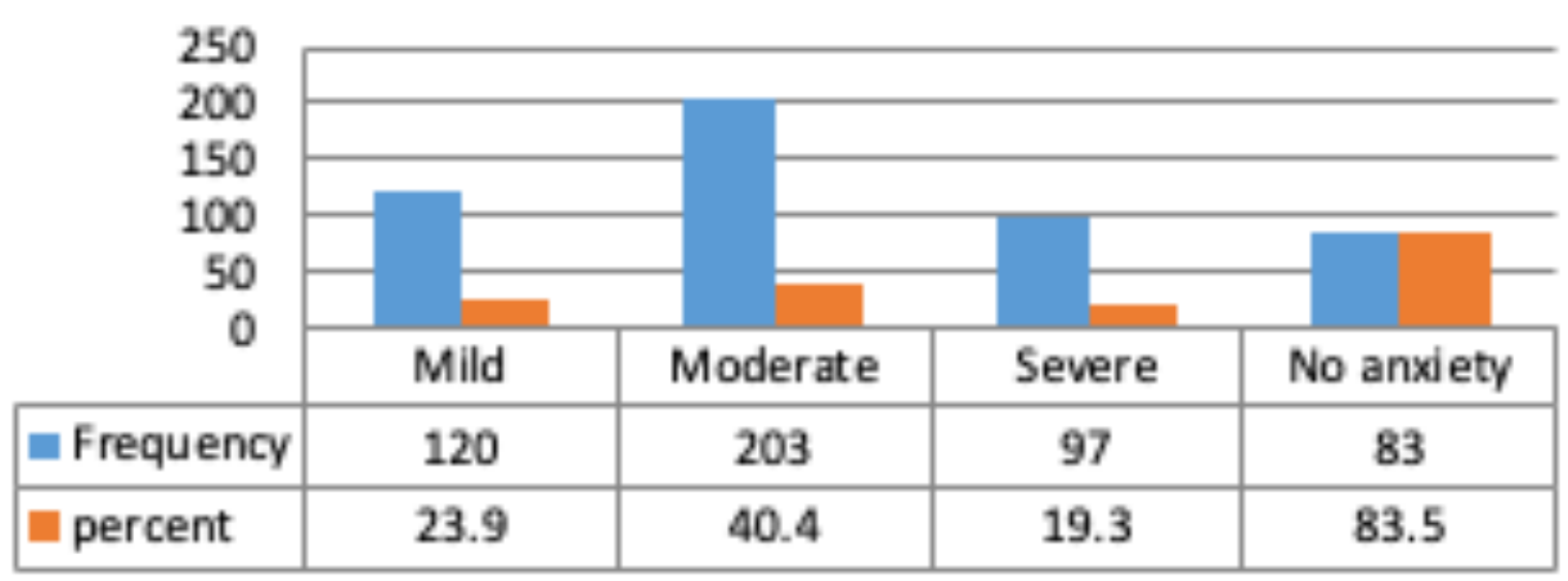


Figure 2: Mean and standard deviation obtained for the dimensions of spiritual intelligence

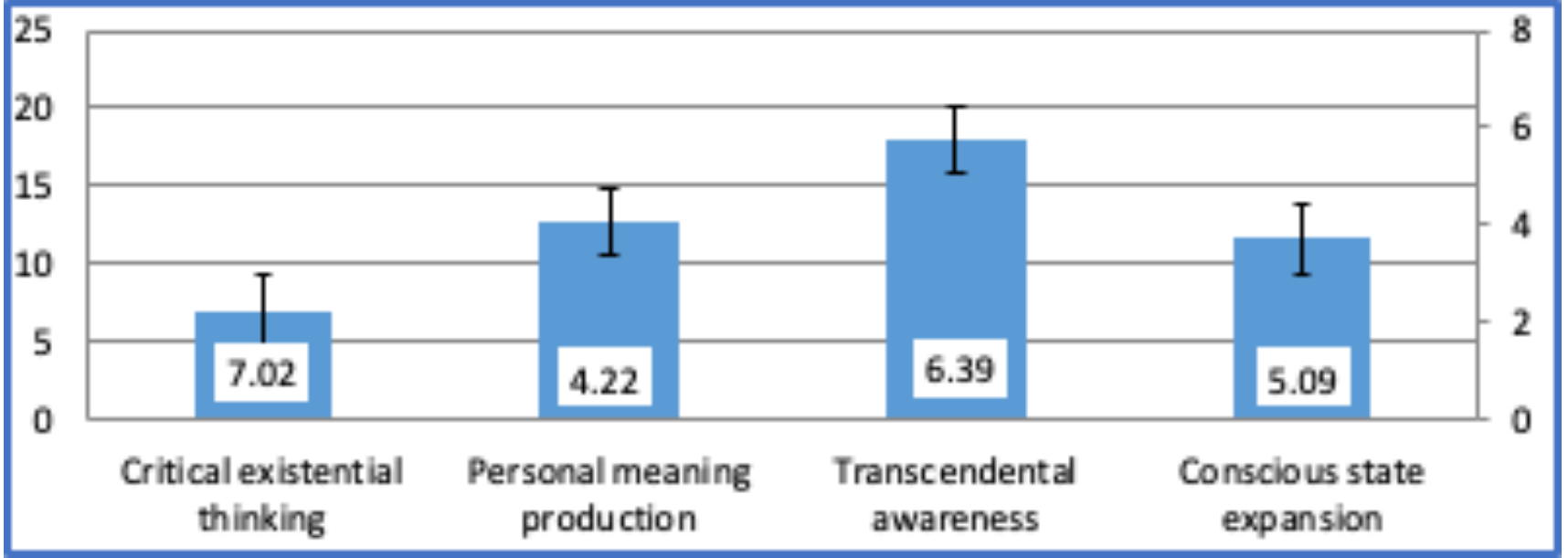

Table 3. The results of Pearson correlation coefficient test for the main research variables

\begin{tabular}{|l|c|c|}
\hline \multicolumn{1}{|c|}{ Variables } & Correlation coefficient or $\mathbf{~}$ & P-Value \\
\hline $\begin{array}{l}\text { Spiritual intelligence with } \\
\text { test anxiety }\end{array}$ & -0.10 & 0.04 \\
\hline $\begin{array}{l}\text { Spiritual intelligence with hidden } \\
\text { anxiety }\end{array}$ & 0.15 & 0.001 \\
\hline Hidden anxiety with test anxiety & -0.043 & 0.33 \\
\hline
\end{tabular}

Figure 1: Results of the path chart developed to examine the relationship between areas of spiritual intelligence and test anxiety (all coefficients are significant at the 5\% level)

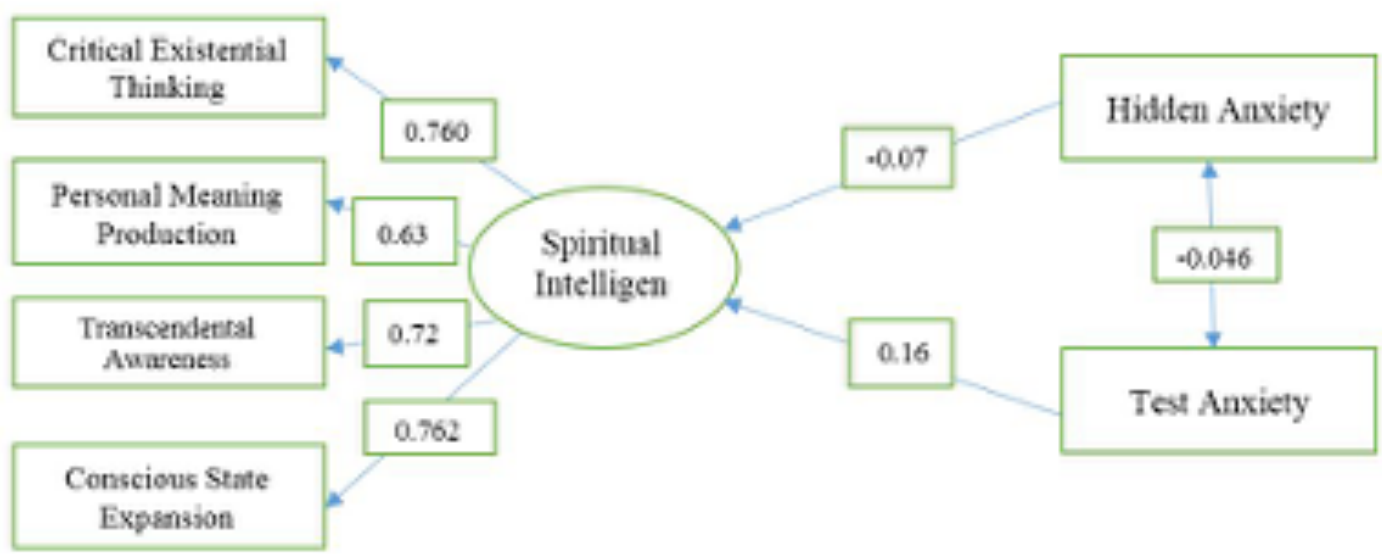

Table 4: Indices of fit of the path analysis model

\begin{tabular}{|l|c|c|c|c|c|c|c|c|c|c|}
\hline Index & RMR & TLI & CFI & BIC & AIC & RMSEA & Chi/df & df & chi \\
\hline Value & 0.021 & 0.990 & 0.944 & 18797.009 & 18725.566 & 0.030 & 1.44 & 8 & 11.561 \\
\hline
\end{tabular}

The values for the general and indirect effects of the studied variables, which are calculated based on the values of the direct effects, are shown in Table 5. 
Table 5. The results of the direct, indirect and general effects of the areas of spiritual intelligence on exam anxiety, hidden anxiety and spiritual intelligence

\begin{tabular}{|c|c|c|c|}
\hline Interaction of domains & Direct effects & Indirect effects & Total effect \\
\hline $\begin{array}{l}\text { Critical Existential Thinking on } \\
\text { Test Anxiety }\end{array}$ & does not have & 0.13 & 0.13 \\
\hline $\begin{array}{l}\text { Critical existential thinking on } \\
\text { hidden anxiety }\end{array}$ & does not have & -0.36 & -0.36 \\
\hline $\begin{array}{l}\text { Critical Intellectual Existential on } \\
\text { Intellectual Thinking }\end{array}$ & 1 & does not have & 1 \\
\hline $\begin{array}{l}\text { Personal meaning production } \\
\text { on Test anxiety }\end{array}$ & does not have & 0.06 & 0.06 \\
\hline $\begin{array}{l}\text { Personal meaning production } \\
\text { on hidden anxiety }\end{array}$ & does not have & -0.01 & -0.01 \\
\hline $\begin{array}{l}\text { Personal meaning production } \\
\text { on spiritual intelligence }\end{array}$ & 0.49 & does not have & 0.49 \\
\hline $\begin{array}{l}\text { Conscious state expansion } \\
\text { on Test anxiety }\end{array}$ & does not have & 0.96 & 0.96 \\
\hline $\begin{array}{l}\text { Conscious state expansion } \\
\text { on hidden anxiety }\end{array}$ & does not have & -0.02 & -0.02 \\
\hline $\begin{array}{l}\text { Conscious state expansion } \\
\text { on spiritual intelligence }\end{array}$ & 0.72 & does not have & does not have \\
\hline $\begin{array}{l}\text { Transcendental awareness } \\
\text { on test anxiety }\end{array}$ & does not have & 0.11 & 0.11 \\
\hline $\begin{array}{l}\text { Transcendental awareness } \\
\text { on hidden anxiety }\end{array}$ & does not have & -0.03 & -0.03 \\
\hline $\begin{array}{l}\text { Transcendental awareness } \\
\text { on spiritual intelligent }\end{array}$ & 0.86 & does not have & 0.86 \\
\hline
\end{tabular}

